\title{
Introduction: Special Issue on 8th European Conference on Precision Agriculture (ECPA)
}

\author{
John V. Stafford · Jim Schepers
}

Published online: 6 January 2013

(C) Springer Science+Business Media New York 2013

The 8th European Conference on Precision Agriculture took place in Prague, Czech Republic at the Czech University of Life Sciences in July 2011. Of all the many papers presented at that conference, a number have been updated and added to with new results and analyses. Some are published in this special issue. Special issues have been a feature of recent ECPA conferences and also for the biennial US conferences. Both conferences now come under the auspices of the International Society for Precision Agriculture. Multidisciplinarity is a feature of Society, Conferences-and this Special Issue! Here you will find an interesting mix of papers on soils, crops, remote sensing and sensing techniques.

J. V. Stafford ( $\square)$

Silsoe Solutions, Ampthill, Bedford, UK

e-mail: john.stafford@silsoe-solutions.co.uk

J. Schepers

USDA-ARS, University of Nebraska, Lincoln, NE, USA

e-mail: james.schepers@gmail.com 